\title{
Electrical Intelligent Fire Safety Early Warning System of Large Complex Building
}

\author{
Fuyuan Mu ${ }^{1, a, *}$, Zhong Wang ${ }^{2}$ \\ ${ }^{1}$ Department Mechanical Engineering, Jinling Institute of Technology, Nanjing, Jiangsu, 211169, China \\ ${ }^{2}$ Nanjing Surui Technology Industry Corporation Limited, Nanjing, Jiangsu, 210000, China \\ a email: mfy@jit.edu.cn \\ *corresponding author
}

Keywords: Large Complex, Intelligent System, Fire Protection

Abstract: This is the difficulty of the application software of its fire protection knowledge system. Then, according to the actual situation, according to the error alarm, the error not only appears, but also the minimum error check of the knowledge fire protection system, the corresponding solutions are put forward. In this way, the fire safety of large complex can be improved.

\section{Introduction}

Hangro Plaza and Tailin project are located in the former Tailin stadium in Tailin City, Tailin Avenue, east of tailon Avenue, west of Xiren Road, south of Xihua road and north of Wusi Avenue. The total planning area is 63400 square meters, and the total construction area is about 371900 square meters, including 22900 square meters of commercial construction area and 26800 square meters of underground part. The project has 7 floors in the shopping mall and the building height is about 60.17 meters. This project belongs to the high-rise building level and the design level is level 1. The project is a circular fire lane, 4 meters wide. There are multiple entrances and exits in the East, South, West and north of the project, so that the evacuated people can directly pass through the outdoor. In order to meet the power supply needs of the project and the region, $60 \mathrm{kV}$ underground substation will be set up on the first floor and the southeast of the underground floor, with a construction area of no more than 5000 square meters.

Table 1 Knowledge teaching content

\begin{tabular}{|c|c|c|}
\hline Project & \multicolumn{2}{|c|}{ Knowledge points } \\
\hline Ideological Education & Relevant laws and regulations & Fire safety management system \\
\hline Basic knowledge of fire & Combustible material & $\begin{array}{c}\text { Combustion supporting } \\
\text { substance }\end{array}$ \\
\hline $\begin{array}{c}\text { Basic knowledge of fire } \\
\text { protection }\end{array}$ & Basic fire prevention knowledge & Common fire hazards \\
\hline Fire alarm & Report to nearby people & Call the fire brigade \\
\hline Fire fighting & $\begin{array}{c}\text { Definition, cause and classification of } \\
\text { fire }\end{array}$ & Fire development process \\
\hline Fire prevention & Preventive measures & Find out the fire hazard \\
\hline Fire hazards & Development process of indoor fire & Fire classification \\
\hline
\end{tabular}

\section{Analysis of Difficulties in the Application of Intelligent System in Large Complex Fire Protection}

\subsection{Large Single-Layer Plane of Fas System}

The single story building area of Dalian Henglong is relatively large[1]. Then, the big story plane of the $\mathrm{f}$ a system ends. This is incomparable with folk buildings. This means that the experience of Fas system design of civil architecture is impossible. Therefore, one of the difficulties in the 
application of intelligent system in large-scale complex fire protection is the large single-layer plane of the system.

\subsection{Fas System is a Multi-Disciplinary and Complex Collaboration System}

Dalian Henglong has many political parties related to design and construction. Finally, as a large-scale complex, in addition to traditional disciplines such as architecture and power lighting, there are also independent systems including security monitoring system and broadcast system. Therefore, it is very important for the specialty to deal with the interface between the specialty and the system.

\subsection{Fas System Needs Higher Segmentation and Consistency}

Dalian Henglong is established by Henglong real estate company. Its management has participated in many parties. In addition, its internal business form is complex, single-sided large face and multiple alarm points [2]. If the system processes fire alarm signals in the fire control center, it is too frequent, and it does not have the investment conditions. In order to quickly and accurately determine the location of the fire, evacuate the personnel in the building, put out the fire in time, set up the alarm detection area, and install the alarm controller. In addition, special requirements, such as merchant's second form of decoration or business type, will also affect the selection, installation and maintenance of related equipment of $\mathrm{F}$ system.

Table 2 Advantages and functions of BIM Technology in different stages

\begin{tabular}{|c|c|c|}
\hline Stage & Advantage & Effect \\
\hline Design phase & $\begin{array}{c}\text { Detect and analyze problems, and the system will } \\
\text { automatically identify and modify them }\end{array}$ & $\begin{array}{c}\text { Guarantee the smooth development } \\
\text { of the project }\end{array}$ \\
\hline $\begin{array}{c}\text { Construction } \\
\text { stage }\end{array}$ & $\begin{array}{c}\text { BIM Technology provides detailed materials and } \\
\text { information to meet the needs of all participants }\end{array}$ & Achieve collaborative work \\
\hline $\begin{array}{c}\text { Operation } \\
\text { stage }\end{array}$ & Maintaining consistency of information at all stages & $\begin{array}{c}\text { Improve the efficiency of project } \\
\text { management and construction }\end{array}$ \\
\hline
\end{tabular}

\section{Application Difficulties and Countermeasures of Fas System}

\subsection{Large Single Floor Area of Fas System}

At this stage, Dalian Henglong introduced the computer monitoring component into the largescale integrated circuit Fas system. In addition, it is important to summarize the power quality of the system, because the system itself has the necessary conditions of good functional robustness and reliability. Dalian Henglong has a large single-layer area, and the system host is far away from its edge. Therefore, alarm loop and Lynch control line are very inclined to line voltage drop. Multiple electronic computers and microprocessors are used in the system[3]. As an electronic component, the disadvantages are obvious. The insulation strength and over-voltage tolerance are poor. In addition, the quality of power supply is required to be high. In the process of operation, under the interference of power supply voltage, frequency mutation, waveform distortion, etc., it is easy to have problems such as false alarm, false check, etc. Therefore, in the system design, it is necessary to check the quality of the power supply to detect the above problems. If the correction method is not implemented from the debugging stage to the correction stage, it is not only the time and manpower consumed, but also completely uncorrectable. Therefore, in the design stage, it is necessary to check the quality of the system power supply, so that the end of the system equipment can work normally and play a role. 
Table 3 Intelligent system construction of complex building

\begin{tabular}{|c|c|c|c|c|c|}
\hline System name & $\begin{array}{c}\text { Southern District } \\
\text { Business }\end{array}$ & $\begin{array}{c}\text { North District } \\
\text { Business }\end{array}$ & $\begin{array}{c}\text { Leisure } \\
\text { Street }\end{array}$ & Hotel & $\begin{array}{c}\text { High rise tower } \\
\text { office }\end{array}$ \\
\hline Generic cabling system & 1 & 1 & 1 & 1 & 1 \\
\hline Computer network system & 1 & 1 & 1 & 1 & 1 \\
\hline $\begin{array}{c}\text { Intelligent video } \\
\text { monitoring system }\end{array}$ & 1 & 1 & 1 & 1 & 1 \\
\hline Anti theft alarm system & 1 & 1 & 1 & 1 & 1 \\
\hline Access control system & 1 & 1 & 1 & 1 & \\
\hline
\end{tabular}

Fas system power bus includes two types of alarm signal line and DC $24 \mathrm{~V}$ power line. There is almost no pressure drop in the alarm signal line[4]. It is often used to send and feedback alarm signals. Power to the remote actuator is not required. Therefore, $1.5 \mathrm{~mm} 2$ copper wire is enough to meet the power on requirements. In addition, the host of Fas system has detailed rules on the total number of alarm circuits, the maximum number of alarm address points and the length of wiring. The signal bus at home and abroad can meet the needs of large-scale complex Fas system. The DC $24 \mathrm{~V}$ power cord is centralized to provide power for the fire fighting link device and control module, including area type. For Hang Lung, it can use regional power. Shortening the power supply distance is not easy to be interfered by voltage drop, which reduces the probability of normal alarm and non operation of the terminal effector. However, there is a disadvantage of using regional power supply, that is, it requires a lot of investment and regular maintenance is more complex.

As a system cabling type, $\mathrm{f}$ includes horizontal and vertical cabling. The type of wiring should be selected scientifically and reasonably. In the case of horizontal wiring, the main circuit is laid vertically on the weak current flow well, and the fire protection device of the floor is guided from the inner sub box of the fire protection area of each floor[5]. All alarm signal lines and DC 24V power lines will not pass through this layer. In the case of using vertical wiring, it is not only necessary to assemble all fire wires in the fire terminal box of 1 floor weak current well, but also to lay each floor vertically through the floor. Horizontal and vertical wiring has its advantages and disadvantages. As for horizontal wiring, since the wiring is arranged on the weaker current axis, the wiring is clear, simple and conservative. Because the vertical wiring is laid with vertical lines on each floor, the layout difference of each floor is not obvious, thus saving lines and easy to build. However, Dalian Henglong is a complex plane and large-scale complex. The shop layout of each shop on each floor is very different. The fire hydrant button and fire fighting equipment on each floor cannot be in the same place. It is understood that the advantages of vertical wiring cannot be realized by using vertical wiring. In addition, the range of fire zone and smoke zone in each floor of Dalian Henglong is different. Each floor has the same place to belong to different businesses. In the case of vertical wiring, daily maintenance cannot be carried out. Abstract: for a large-scale and complex Fas system like Dalian Henglong, horizontal wiring should be selected.

\subsection{Analysis of the Cooperation between the Subjects of Fas System and Experts}

Dalian Henglong has many political parties related to design and construction. Finally, as a large-scale complex, in addition to traditional disciplines such as architecture and power lighting, there are also independent systems including security monitoring system and broadcast system[6]. If the design link lacks detailed design documents, in order to clarify the relevant professional interfaces and interfaces, it will lead to the fire protection equipment can not fully perform their tasks.

It has safety monitoring system, garage parking management system and traffic control system. In the case of fire, the existence of traffic control system can prevent people in the building from evacuating in time. Therefore, it must be connected to the main frame of Fas system. In the event of a fire, it can quickly break the restrictions of systems such as traffic control, and quickly evacuate people. According to the fire rules, the system will also shut down non fire[7]. If firefighters catch the fire, they can't burn it. On the one hand, it does not harm others, on the other hand, it protects itself. 
In the design of Fas system, although the monitoring focus is set on fire pump and fire pump, the monitoring of pressure stabilization pump, pressure of water supply pipe network, liquid level of water storage tank and fire-fighting ability of fire-fighting equipment are ignored. In case of fire, fire pump and fire pump are needed, so the monitoring of power supply must be focused every day. As a result, under normal circumstances, fire pumps and spray pumps are not used, and of course, their shortcomings can not be found. In terms of fire, there will be problems, the operation is not smooth, the fire-fighting time will be delayed, and serious casualties will be caused[8]. Therefore, the Fas system shall be equipped with fire equipment inspection and monitoring functions to confirm whether there is a fault, and if there is a fault, it shall be repaired immediately. In addition, attention must be paid to the monitoring of the fire water tank. The monitoring of fire water tank is not only the liquid level, but also the water temperature. Because talian is a city in the north, the temperature in winter is very low even though it is by the sea. In order to prevent being frozen by water temperature, prevent normal use and delay fire rescue.

Some control objects of Fas system are arranged in AC 220V or AC 316v equipment, such as power distribution control box (such as power pump or elevator)[9]. As for the control object of this species, according to the output control automatic alarm system, the link module level maintenance state cannot be selected, but the control command of pulse output cannot be selected. According to the control object's own control equipment, it must be completed. Even if the output signal no longer appears, the controlled object can still work normally. Because this device is particularly important, it is necessary to prevent the Fas from setting the stop function. The system can also control the elevator, but only the forced landing module facing the fire is set. If the elevator stops at the first floor, the signal feedback module is not set. In the face of fire, people take the elevator to the first floor and leave, but because there is no signal feedback module, then the fire control center can not immediately disconnect the power supply of the elevator, resulting in live fire-fighting work, increasing the risk. Similar to this is the electric fire damper set in the gas fire extinguishing room. Therefore, this kind of fire-fighting facilities can not only control its own functions, but also feedback the signal to the fire control center as soon as possible, so as to make a more reasonable fire-fighting plan.

\subsection{Partition and Consistency of Fas System}

In addition to some small and medium-sized enterprises, there are also many large-scale businesses, theatres and so on in large-scale complexes like thalian Hamburg. The theatre is located on the southwest corner of the 4th to 7th floors, with a total of 10 auditoriums. No more than 1800 seats. There are also skating rinks and shopping malls. This large-scale businessman has the same characteristics: first, it has a large footprint; second, it has a lot of passengers and high density[10]. If the Fas system does not take measures to the area, the large-scale merchants' unified fire alarm will cause system confusion. In addition, it will not try its best to manage, and in case of fire, please evacuate in time and do not extinguish the fire source. Therefore, it is necessary for these businessmen to divide the Fas system, set up the business management room, set up the regional alarm controller, and arrange special personnel.

As a listed Real Estate Company, it has been very mature. If the owner chooses the Fas system brand, it is necessary to combine the characteristics of the brand when designing the real estate and F system of block A. therefore, there are as many technical characteristics of the product as possible. In order to emphasize the competition between the design and the actual function, this one is different. The technical features of Fas products are ring wiring, branch wiring and ring branch compatible wiring. In order to have larger single-layer area and more complex form, Dalian Henglong chose the third type. Second, the modules are divided into single type and box type. The latter has many design drawings, but daily maintenance is simple and fast. Third, different types of products, a circular address, the total number of input and output points are also very different. Therefore, in the design process, address level, input point and output point need to be processed according to the protection level. Balance. 


\section{Conclusion}

Generally speaking, the difficulty of applying intelligent system to such large-scale and complex fire protection as Dalian Henglong is that the large-scale single-layer plane of Fas system, the composite specialty of Fas system, the complex cooperation and the reflection of the segmentation and consistency of Fas system are high conditions. In view of this difficulty, attention should be paid in the design. The difficulties faced by the large single-layer plane, and the modification of the system power quality of the bus power supply, power capacity analysis, and the selection of horizontal wiring types need attention. It is necessary to pay attention to the cooperation interfaces and interfaces of relevant disciplines. Then, security, water, fire fighting, mainly for cooperation and attention. The high segmentation and consistency conditions faced by the region are focused on the use of alerts that need to be noted and the technical features of the product given to the full game.

\section{Acknowledgements}

2014 Jiangsu University Natural Science Foundation Project "Research on Key Technologies of Intelligent Fire Protection System Based on Big Data and Mobile Communication Network" (14KJD620001).

\section{References}

[1] Wu C Z, Wei X G, Wu M Q. Large Efficient Intelligent Heating Relay Station System, 2017.

[2] György Schuster, Daniel Tokody, Imre János Mezei. Software Reliability of Complex Systems Focus for Intelligent Vehicles, 2017.

[3] Lou D, Weiland S. Parametric model order reduction for large-scale and complex thermal systems, 2018.

[4] Nikivincze I. Dana Ulery: Pioneer of Statistical Computing and Architect of Large, Complex Systems, vol. 39, no. 2, pp. 91-95, 2017.

[5] Sha Hu, Fredrik Rusek, Ove Edfors. Beyond Massive MIMO: The Potential of Positioning With Large Intelligent Surfaces. IEEE Transactions on Signal Processing, no. 99, 2017.

[6] Lian J, Yang Y, Shaowei H U, et al. Research Progresses and Frontiers on Control and Safety Operation of Super-large Hydraulic Complex, 2017.

[7] Thuy N. Modelling and Simulation of the Dynamics of Complex Socio-Cyber-Physical Systems and Large Scale Systems of Systems all Along Their Lifetime, 2017.

[8] James Brook, Felix Cuadrado, Eric Deliot, Loom: Complex large-scale visual insight for large hybrid IT infrastructure management. Future Generation Computer Systems, vol. 80, 2017.

[9] WANG Yunjia. Research Progress and Prospect on Ecological Disturbance Monitoring in Mining Area. Acta Geodaetica Et Cartographica Sinica, 2017.

[10] Xin J, Zhao K, Ji J, et al. Design and implementation of Intelligent transplanting system based on photoelectric sensor and PLC, 2018. 